\title{
A multi-diagnostic approach to understanding high-latitude plasma transport during the Halloween 2003 storm
}

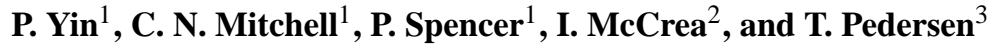 \\ ${ }^{1}$ Department of Electronic and Electrical Engineering, University of Bath, Bath, BA2 7AY, UK \\ ${ }^{2}$ Space Science and Technology Department, Rutherford Appleton Laboratory, Chilton, Oxfordshire, OX11 0QX, UK \\ ${ }^{3}$ Space Vehicles Directorate, Air Force Research Laboratory, Hanscom Air Force Base, MA, USA
}

Received: 19 October 2007 - Revised: 1 August 2008 - Accepted: 11 August 2008 - Published: 15 September 2008

\begin{abstract}
During the Halloween 2003 storm event, significant electron density enhancements at elevated F-layer altitudes were recorded by the EISCAT and ESR radars in northern Europe between 20:00 and 24:00 UT on 30 October. At the same time, a sequence of optical images from Qaanaaq in northern Greenland captured a series of eastward-propagating polar cap patches. In this paper, an advanced 4-D tomographic method based on the assimilation of global GPS data, coupled to a predictive Kalman filtering technique, has been used to reveal the linkage between these ionospheric structures. The combination of the various data sources has clearly established the time history of this extreme event, in which high-density plasma was uplifted in the dayside ionosphere and convected anti-sunward across the polar cap to European high latitudes at an elevated F-layer. Using this multi instrument approach, we can differentiate between those density structures observed at the ESR which occurred as a result of cross-polar transport and those more likely to have been produced by in-situ soft particle precipitation, a distinction which is supported by the ESR and EISCAT data. The multi-diagnostic approach reported here has the potential significantly to extend our current understanding of high latitude plasma transport and the origin of electron density enhancements.
\end{abstract}

Keywords. Ionosphere (Ionospheric disturbances; Plasma convection; Polar ionosphere)

\section{Introduction}

During major geomagnetic storms with southward IMF orientation, reconnection occurs between the magnetosphere and the solar wind, resulting in a large energy transfer through the open magnetic field into the polar ionosphere.

Correspondence to: P. Yin

(eexpy@bath.ac.uk)
In response, the polar ionosphere becomes dominated by convection and, when seen from a single location, the electron density appears highly variable because of plasma transportation and precipitation. Observations of plasma structures are frequently associated with large-scale polar cap patches (Rodger et al., 1994; Crowley, 1996) and the Tongue of Ionisation (TOI). They can be fast moving and often drift under the influence of an expanded high-latitude convection pattern into the polar regions.

The Halloween 2003 storm was one of the most intense geomagnetic disturbances ever recorded. Lasting more than three days, with $K_{p}$ as high as 9 and $D_{s t}$ below $-400 \mathrm{nT}$, this storm event had profound effects, both geophysically and in terms of its impact on operational systems (see for example Doherty et al., 2004). The American Geophysical Union (AGU) published special issues of the Journal of Geophysical Research (JGR) and Geophysical Research Letters (GRL) dedicated to results from the October and November 2003 storms. For example, Foster and Rideout (2005) found that GPS Total Electron Content (TEC) greatly increased by up to 200 TEC units (TECu) over the west coast of the US on 30 October, and a study on ionospheric scintillation in the polar ionosphere during the Halloween storm period was carried out by Mitchell et al. (2005).

Here we present the data from the EISCAT (European Incoherent SCATter) Svalbard Radar (ESR) and the EISCAT mainland UHF radar at Troms $\varnothing$, recorded during the second night of this intense disturbance. In addition, global dualfrequency GPS measurements provided by the International GNSS Service (IGS) are used together with a 4-D tomographic algorithm (Multi-Instrumental Data Analysis System - MIDAS) to investigate the source of the high-density plasma observed by the two EISCAT radars. This technique has been used extensively to study three major storms (Yin et al., 2006) and verified over the mainland USA using the Millstone Hill ISR (Incoherent Scatter Radar) data for the July 2000 storm (Yin et al., 2004). We will demonstrate that,

Published by Copernicus Publications on behalf of the European Geosciences Union. 
when the optical and radar results are combined with global GPS data, the generation and transport of these ionospheric structures can be accurately traced and reconstructed.

The ESR (Wannberg et al., 1997) is a dual-dish radar operating at $500 \mathrm{MHz}$. One dish (the $32 \mathrm{~m}$ ) can scan freely in azimuth and elevation, while the other ( $42 \mathrm{~m}$ ) dish is fixed along the direction of the local magnetic field. The mainland EISCAT UHF system (e.g. Rishbeth and Williams, 1985) is a tristatic radar system operating at $928 \mathrm{MHz}$, consisting of a transmit/receive site at Troms $\varnothing$, Norway and passive receiver sites at Kiruna, Sweden and Sodankylä, Finland. At each site, the antennas are fully steerable $32 \mathrm{~m}$ dishes, similar to the steerable dish of the ESR. In this case, we show data from the $42 \mathrm{~m}$ dish of the ESR and the Troms $\varnothing$ radar of the mainland UHF system, both of which were measuring parallel to their local magnetic field lines, and from the $32 \mathrm{~m}$ dish of the ESR, which was scanning between three directions: eastward, southward and vertically upward. ISR observations of this kind have frequently been used to identify polar patches and auroral blobs, but such measurements alone are not sufficient to explore the processes by which such enhancements are created.

Further observations during part of this interval have been obtained from optical instrumentation, through all-sky imaging of the $\mathrm{O}\left({ }^{1} \mathrm{D}\right) 630.0 \mathrm{~nm}$ emission. This emission results from recombination of dense plasma, at least away from areas of auroral precipitation. As the recombination producing this emission depends on densities of both the neutral atmosphere and the plasma, the final intensity is influenced by both the density and altitude of the F-region plasma (Sojka et al., 1997). However, in most cases when patches are present the structure apparent in the images agrees qualitatively with the large-scale structure in the plasma density. This will be discussed in more detail in Sect. 3.3.

\section{GPS tomography}

Dual-frequency ground-based GPS measurements provide the principal data source for the tomographic inversion technique used in this paper. Differential phase observations are firstly used to derive the slant TEC data between the ground receivers and GPS satellites and are then used as the direct input to the tomography. In this new version of the MIDAS algorithm (Spencer and Mitchell, 2007), the ionosphere is defined by voxels of constant electron density with a variable resolution (here, $4^{\circ}$ in geographic latitude, $4^{\circ}$ in geographic longitude and $40 \mathrm{~km}$ in altitude). In addition, a rotation matrix is applied to move the geographic grid formed at the equatorial region to the high-latitude regions and a mathematically-modelled set of three EOFs (Empirical Orthogonal Functions) is used to represent the ionosphere in the radial direction. Spencer and Mitchell (2007) describe further details of this method. Because of the grid resolution, only macroscale or mesoscale plasma structures can be tracked at intervals of 10 min by this tomography method. The actual image resolution will vary across the grid according to the receiver and satellite configuration. A review of GPS imaging of the ionosphere is given in Bust and Mitchell (2008).

In order to continuously capture moving structures in the high-latitude regions, a Kalman filter and a forward projection of the solution, based on a model plasma drift velocity field, have been incorporated into the algorithm to track the time varying transport of those structures. The Weimer model (Weimer, 1995) has been introduced to provide electrostatic potential at high latitudes so that an estimate of $\boldsymbol{E} \times \boldsymbol{B}$ plasma drift velocity can be derived to forward project the estimate of the ionospheric density at each point in time. The Weimer model is driven by IMF components $\left(B_{y}\right.$ and $B_{z}$ ) and solar wind parameters measured by the ACE spacecraft, allowing the high-latitude plasma to be guided in the algorithm by the resultant convection patterns. The use of the model compensates for the poor coverage of ground GPS measurements over the polar areas, by creating an a priori estimate based upon a convected version of the previous image.

\section{Multi-instrument observations}

\subsection{Incoherent Scatter Radar observations}

Localised high-resolution ISR observations are used to obtain accurate plasma densities and temperatures in the ionosphere. Figure 1 shows the electron densities (upper panel) and temperatures (lower panel) measured by the EISCAT Svalbard radar between 20:00 and 24:00 UT on 30 October 2003. The time interval between these measurements is $128 \mathrm{~s}$, but because of the way that the experiment was configured, measurements were only made on the $42 \mathrm{~m}$ antenna during $64 \mathrm{~s}$ of each $128 \mathrm{~s}$ period, with the remaining $64 \mathrm{~s}$ being used to make measurements with the $32 \mathrm{~m}$ dish. The data from the ESR $32 \mathrm{~m}$ antenna will be discussed in Sect. 4.

The upper panel of Fig. 1 shows that two particularly striking high-density plasma structures are observed by the ESR between 20:00 and 24:00 UT. The first of these was seen at around 21:00 UT with a large enhancement in electron density lasting more than half an hour, while the later enhancement lasting several minutes, occurred at about 23:00 UT. In addition to the significant increase in electron density, the Flayer peak heights during these events were elevated to above $400 \mathrm{~km}$. The electron temperatures, however, as shown in the lower panel of Fig. 1, were quite low during the first of these enhancements, while the second density enhancement coincided with a strong increase in electron temperature. Simultaneous enhancements of electron density and temperature can be explained by the local influence of soft particle precipitation, however low electron temperatures are consistent with the idea that density enhancements were not created 

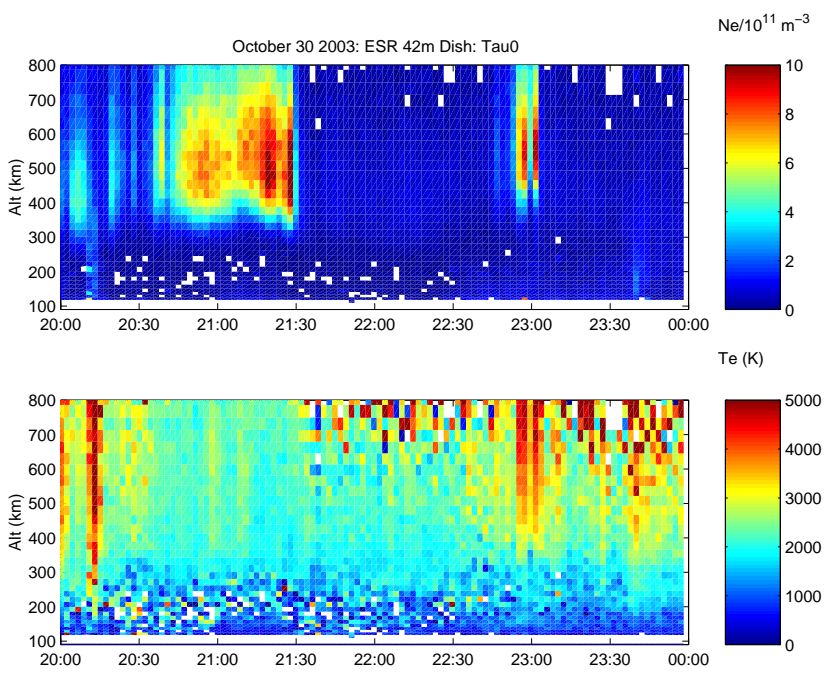

Fig. 1. Electron densities (upper panel) and electron temperatures (lower panel) measured by the EISCAT Svalbard $\left(78^{\circ} \mathrm{N}, 16^{\circ} \mathrm{E}\right)$ radar between 20:00 and 24:00 UT on 30 October 2003 .

in-situ but had had time to cool down and thermalise in the course of being convected from a distant source.

Figure 2 shows the electron densities (upper panel) and temperatures (lower panel) measured by the EISCAT mainland UHF radar at Troms $\varnothing$ between 20:00 and 24:00 UT on 30 October. What is very interesting about this event is that two very similar electron density features were observed by the EISCAT UHF radar at Troms $\varnothing$, in each case around 30 min later than the events seen by the ESR. In both cases the densities were extraordinarily high - around $10^{12} \mathrm{~m}^{-3}$, but the electron temperatures were low; indeed there was a clear anti-correlation between the density and the electron temperature during these periods, indicating that in-situ particle precipitation was not occurring in these cases. It appears that these enhancements consisted of normal ionospheric plasma, though at very high density. It is notable that the timing of the events is such that they were first seen at Svalbard, then subsequently at Troms $\varnothing$, consistent with them being the signatures of high-density plasma enhancements being transported southward. One might expect from the appearance of such enhancements in the midnight sector that they were transported by cross-polar convection from the dayside (US) sector. In the following sections, we show how we have used the data sets described above to trace the origin and history of this plasma.

\subsection{GPS imaging results}

Figure 3 illustrates GPS TEC maps derived over the Northern Hemisphere for times of 20:20, 21:00 and 21:40 UT. The plasma velocity vectors derived from the Weimer model are also shown. In the dayside ionosphere, large amounts of high-density plasma are produced over the North American
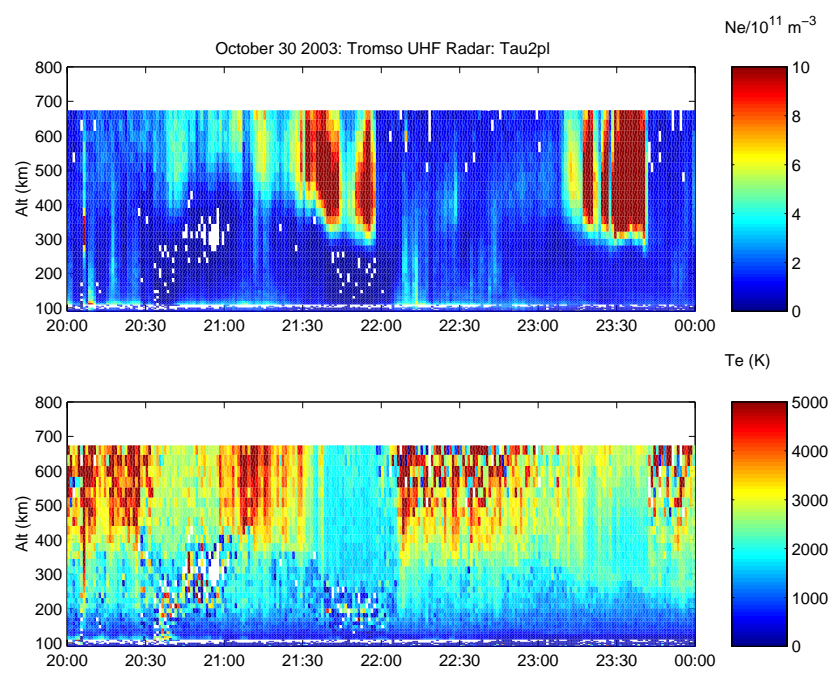

Fig. 2. Electron densities (upper panel) and electron temperatures (lower panel) measured by the EISCAT Troms $\emptyset\left(69^{\circ} \mathrm{N}, 19^{\circ} \mathrm{E}\right)$ radar between 20:00 and 24:00 UT on 30 October 2003 .

continent by solar photo-ionisation at 20:00 UT (local afternoon). The maximum TEC exceeded 120 TECu at 20:20 UT over the western US and about $80 \mathrm{TECu}$ at higher latitudes as shown by the colour scale in Fig. 3a.

The Weimer model predicts an expanded twin-cell convection pattern, which allows the ionisation produced by solar radiation at the lower latitudes in the dayside ionosphere to become entrained into the high-latitude convection pattern. In consequence, a Tongue of Ionization (TOI), which is clearly seen in all three TEC maps, is carried from the dayside over the pole towards the nightside between 20:20 and 21:40 UT. The GPS imaging suggests that the horizontal transport of this plasma is dominant during this time, driven by the convection electric field. It is also likely that precipitation further enhanced the densities as the plasma entered the polar region. During the period from 20:20 to 21:40 UT, the convection pattern expanded equatorward and the cross-polar flow carried this plasma anti-sunward from North America into Greenland, then across Svalbard, finally arriving at Troms $\varnothing$, where the convecting plasma structures were captured by the ESR and EISCAT radar as the first of the two density enhancements in Figs. 1 and 2, respectively. Around 20:40 UT, when the first plasma density enhancement was observed at Svalbard, the Weimer model predicted eastward plasma velocities up to $1000 \mathrm{~m} / \mathrm{s}$ and southward velocities exceeding $550 \mathrm{~m} / \mathrm{s}$.

\subsection{Optical images showing the drift of polar cap patches}

Further evidence for cross-polar transport of high-density plasma structure is provided by a sequence of images taken by the optical instrumentation at Qaanaaq, Greenland $\left(77.5^{\circ} \mathrm{N}, 69^{\circ} \mathrm{W}\right)$. Figure 4 shows a sequence of $630.0 \mathrm{~nm}$ 

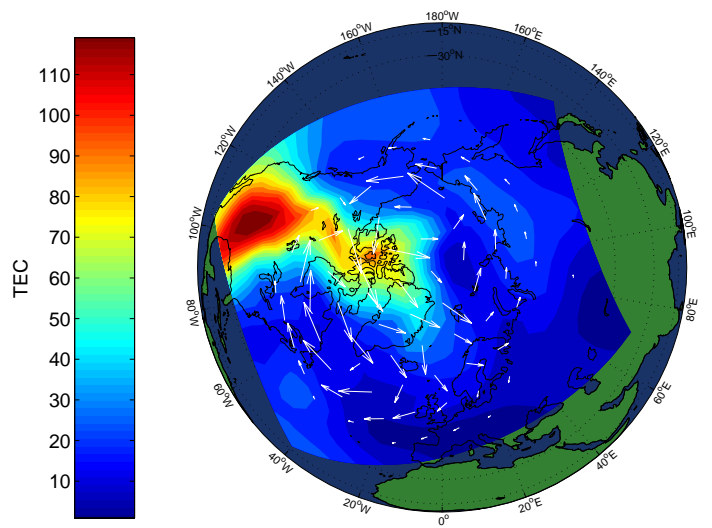

Total Electron content 30-Oct-2003 20:20:00UT

(a) 20:20UT
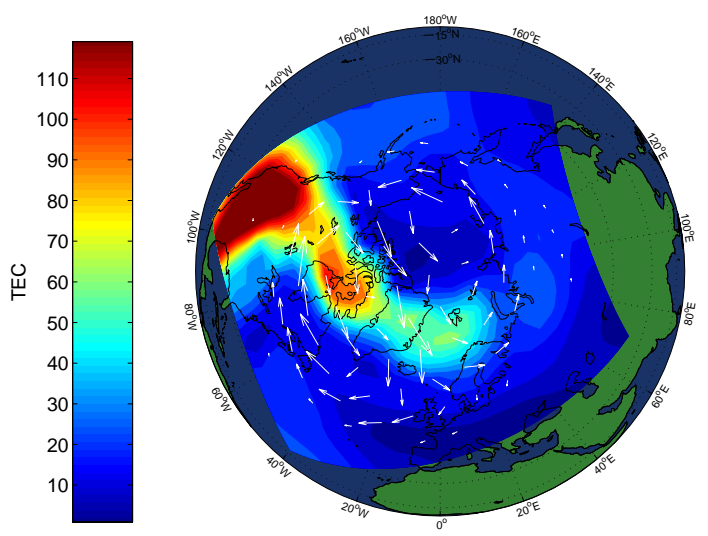

Total Electron content 30-Oct-2003 21:00:00UT

(b) 21:00UT
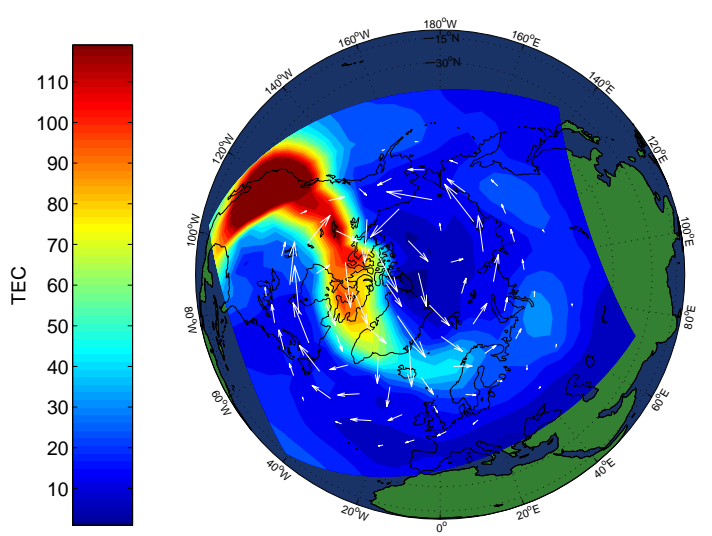

Total Electron Content 30-Oct-2003 21:40:00UT

(c) $21: 40 \mathrm{UT}$

Fig. 3. GPS TEC maps (in TECu) over the Northern Hemisphere showing the plasma transported anti-sunward from the dayside ionosphere across the polar cap, then arriving Northern Europe, for the period of (a) 20:20 UT, (b) 21:00 UT and (c) 21:40 UT on 30 October 2003.

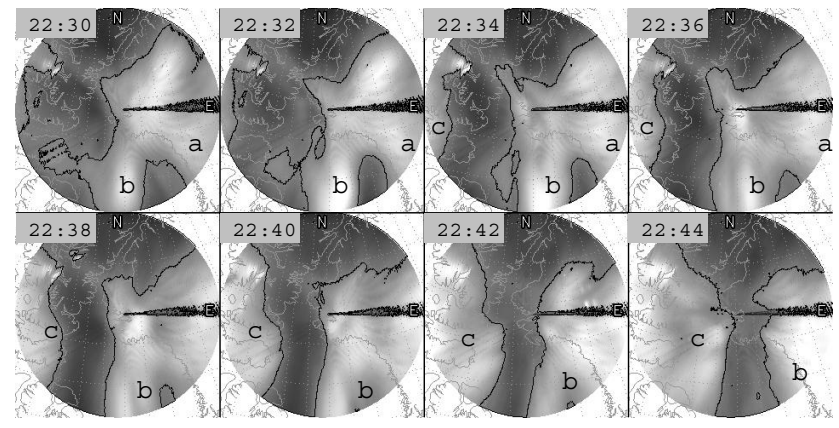

Fig. 4. A sequence of $630.0 \mathrm{~nm}$ all-sky optical images for the period 22:30 to 22:44 UT on 30 October 2003, mapped to geographic coordinates using an assumed emission altitude of $250 \mathrm{~km}$. Images were collected every $2 \mathrm{~min}$ from Qaanaaq, Greenland $\left(77.5^{\circ} \mathrm{N}, 69^{\circ} \mathrm{W}\right)$.

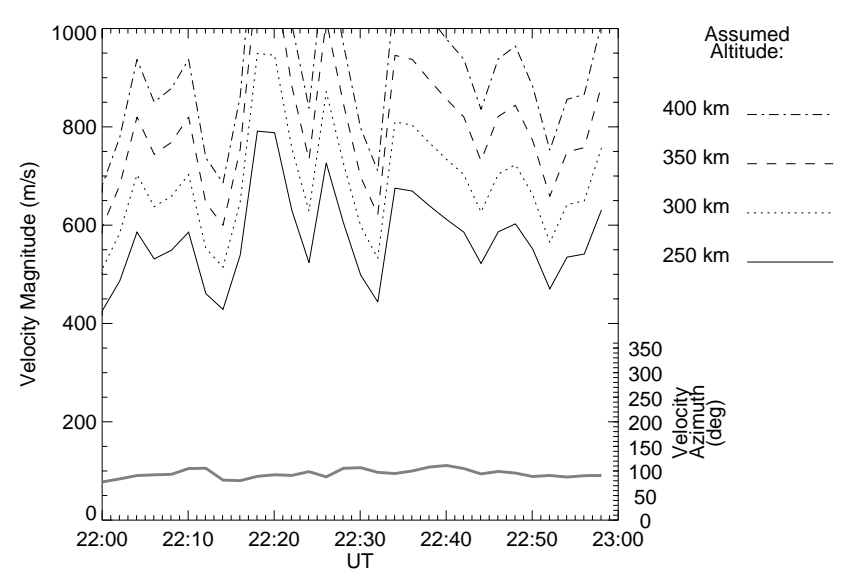

Fig. 5. Optically determined average plasma drift velocities over Qaanaaq, Greenland for a range of assumed altitudes. The thick gray line near the bottom gives the azimuth of the velocity vector, which was generally eastward or slightly south of east.

all-sky optical images, collected every two minutes during the period 22:30 to 22:44 UT on 30 October 2003, mapped to geographic coordinates using an assumed emission altitude of $250 \mathrm{~km}$. A series of patches (bright areas labelled a, $\mathrm{b}$, and c) is clearly visible, separated by darker regions of low plasma density. A contour line has been drawn in each image at the average intensity to aid the eye in following the generally eastward motion of the features with time. The black wedge pointing east is an ionosonde antenna tower.

Figure 5 illustrates the optically determined average plasma drift velocities over Qaanaaq from 22:00 to 23:00 UT for a range of assumed altitudes. The thick gray line near the bottom gives the azimuth of the velocity vector, which was generally eastward or slightly south of east. Average velocities were determined from the optical data by performing cross-correlations between difference images, eliminating background features and non-moving artifacts such as light contamination. An average velocity vector for the entire field of view was computed every two minutes, providing 
a magnitude and direction. As the altitude of the emission layer cannot be determined from a single imager, the pixel velocity is displayed in Fig. 5 for a number of possible emission altitudes. The plasma velocity is well over $500 \mathrm{~m} / \mathrm{s}$ for emissions at $250 \mathrm{~km}$ altitude, and rises to more than $800 \mathrm{~m} / \mathrm{s}$ for an emission altitude of $400 \mathrm{~km}$. Given the altitude at which the patches were observed when they reached the ESR, it would seem that the assumption of emission altitudes above $400 \mathrm{~km}$ is not unrealistic for this storm time event.

GPS TEC maps in the Northern Hemisphere for times of 22:40, 23:20 and 23:40 UT are shown in Fig. 6a, b and c, respectively. The TEC map in Fig. 6a suggests that the highdensity plasma convecting from high latitude Canada toward the west of Greenland had drifted across Qaanaaq and covered much of southern Greenland by 22:40 UT. The transit of this large-scale density structure was well detected by the $630.0 \mathrm{~nm}$ optical instrument as illustrated in Fig. 4. Figure 6b and $\mathrm{c}$ then shows how the region of enhanced TEC continued to drift equatorward, weakening steadily as it entered the European sector. These GPS maps indicate a velocity of $\sim 850 \mathrm{~m} / \mathrm{s}$ in the region of Qaanaaq, in good agreement with the velocity derived from the optical images if a high emission altitude is assumed.

3.4 GPS TEC comparisons at three observing sites (Qaanaaq, Svalbard and Troms $\varnothing$ )

Figure 7 shows time series of the observed GPS TEC changes at the three observing sites (Qaanaaq, Svalbard and Troms $\varnothing$ ). At Qaanaaq, the TEC increased from 10 to $40 \mathrm{TECu}$ at 19:30 UT and then continuously rose up to $80 \mathrm{TECu}$ in one hour, as enhanced plasma convected from the dayside ionosphere through the polar region. Between 20:00 and 22:00 UT, high TEC started to be seen at Svalbard and Troms $\varnothing$ where it was also identified by the two EISCAT radars.

As shown in Figs. 6a and 7a, a second large TEC enhancement was seen over Greenland between 22:00 and 23:00 UT. This TEC enhancement corresponds with eastward-moving intensity enhancements seen in the $630.0 \mathrm{~nm}$ emissions over Qaanaaq with the all-sky imager between 22:00 and 24:00 UT, as shown in the upper panel of Fig. 8. The lower panel of Fig. 8 compares GPS TEC and optical measurements along similar lines of sight, although from sites separated by $\sim 1^{\circ}$ in latitude. The TEC measurements were mapped along the satellite link to an assumed centroid altitude of $350 \mathrm{~km}$, while the optical data from Qaanaaq was converted into geographic coordinates at an assumed altitude of $250 \mathrm{~km}$. While there is no clear one-to-one correspondence between these two data sets as a result of the sites being significantly separated, the similar time histories are suggestive of the general structure observed being similar. Both data sets show a large enhancement, containing some degree of structure, which lasted approximately $20 \mathrm{~min}$. Both the TEC and optical data show that there is structure within this
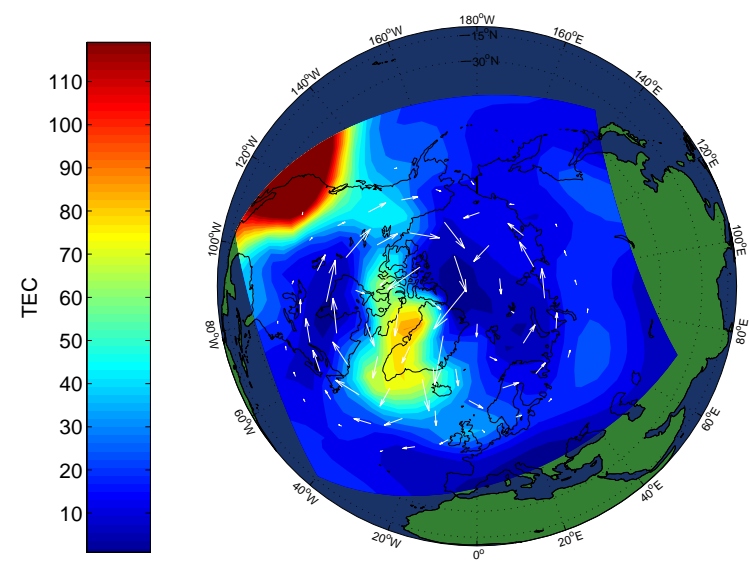

Total Electron content 30-Oct-2003 22:40:00UT

(a) 22:40UT
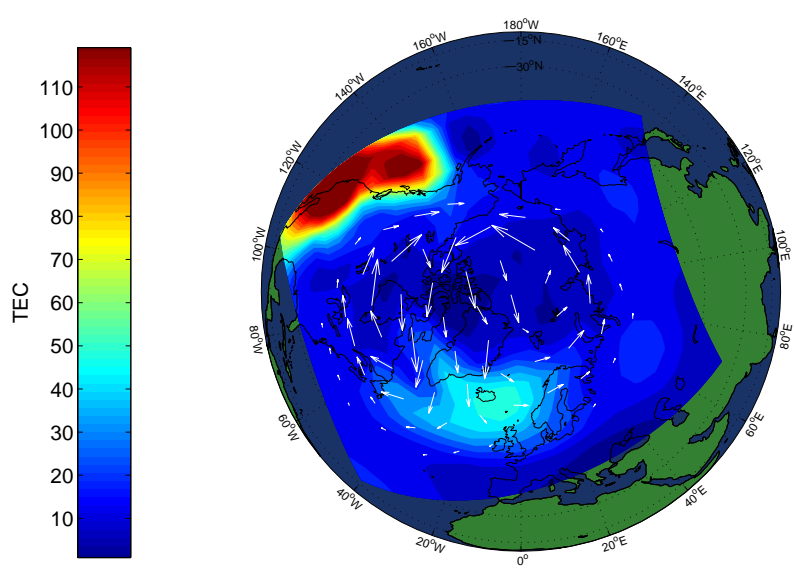

Total Electron Content 30-Oct-2003 23:20:00UT

(b) $23: 20 \mathrm{UT}$
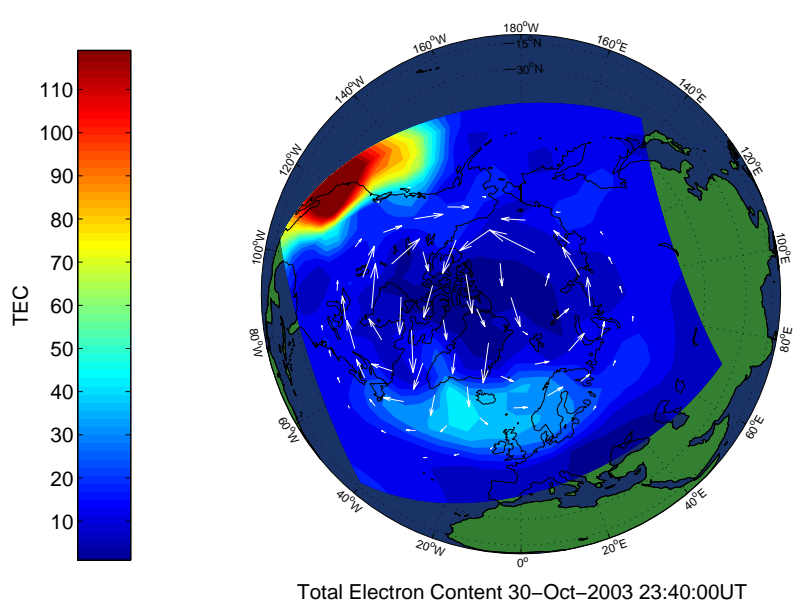

(c) $23: 40 \mathrm{UT}$

Fig. 6. GPS TEC maps (in TECu) over the Northern Hemisphere for the period of (a) 22:40 UT, (b) 23:20 UT and (c) 23:40 UT on 30 October 2003. 


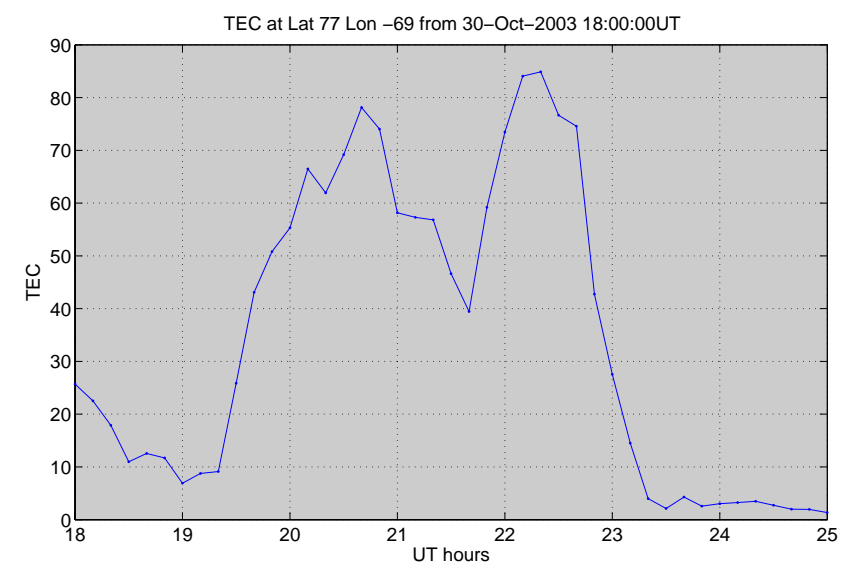

(a) Qaanaaq

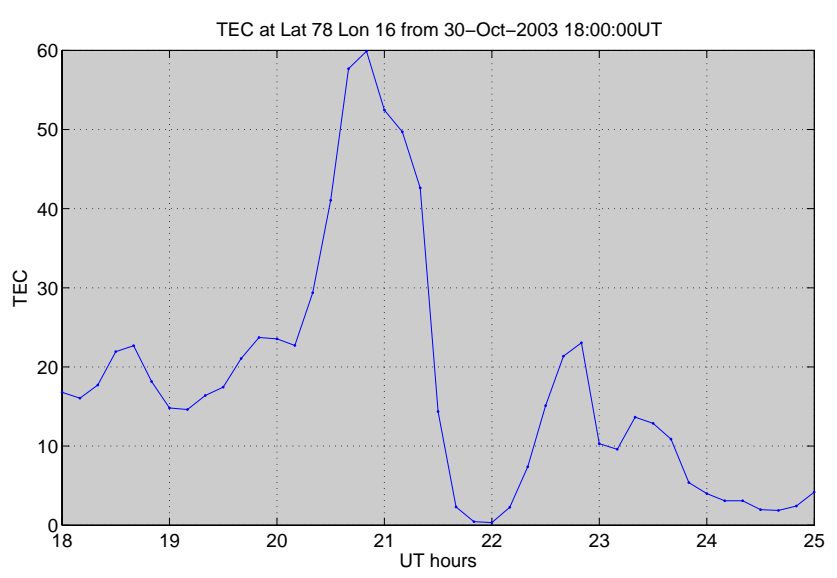

(b) Svalbard

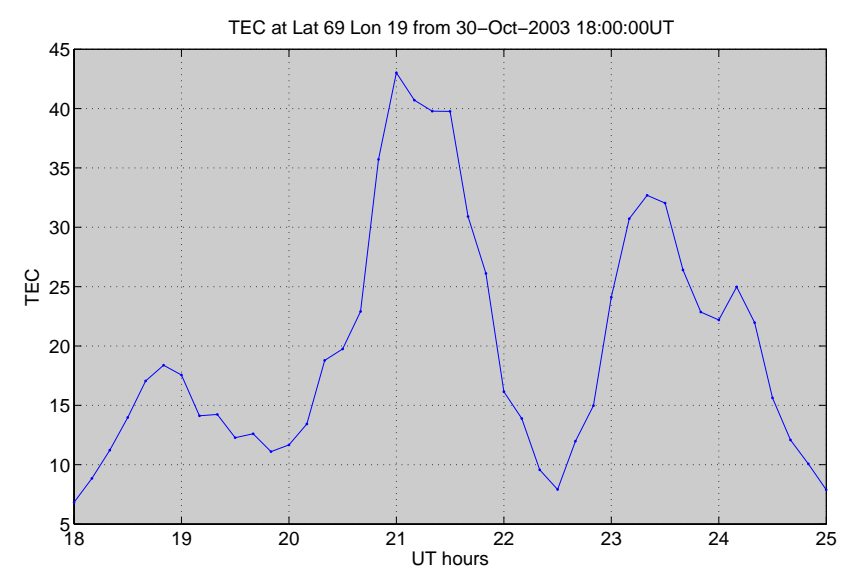

(c) Tromso

Fig. 7. GPS TEC variations (in TECu) from 18:00 UT 30 October to 01:00 UT 31 October for three locations: (a) Qaanaaq, (b) Svalbard and (c) Tromsø.

feature, as well as two or three smaller enhancements prior to the largest enhancement. One possible interpretation, supported by the GPS TEC maps, is that the TOI had broken
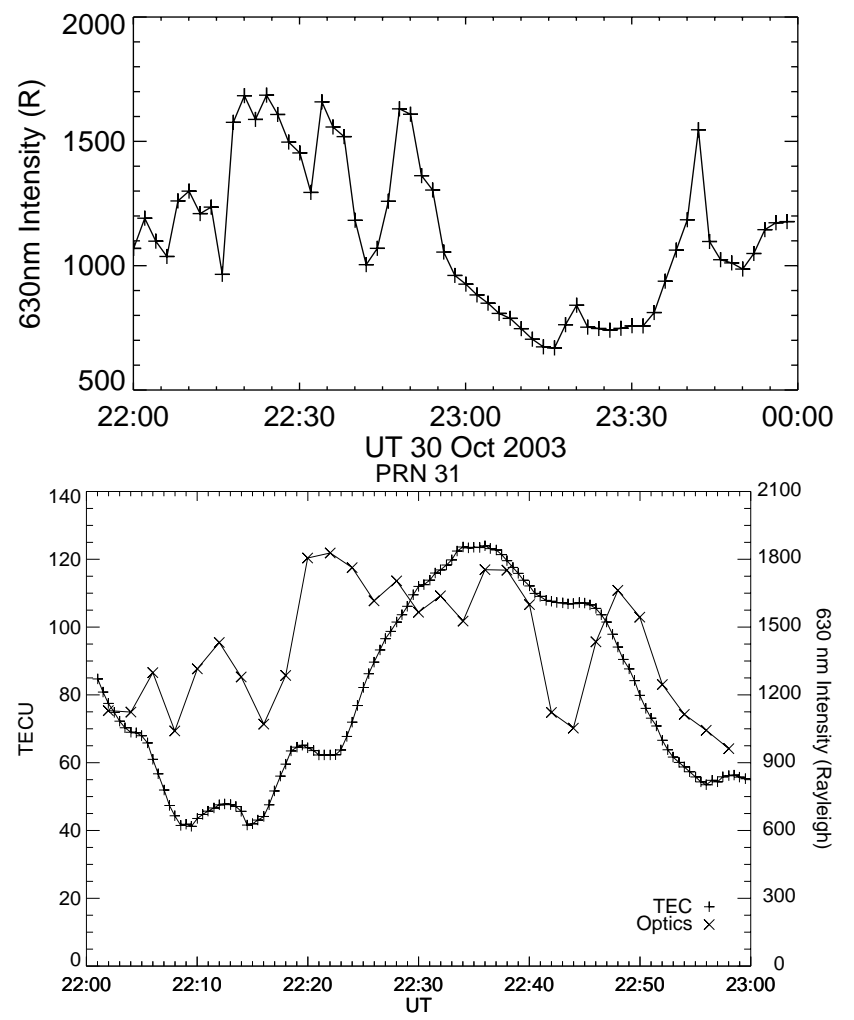

Fig. 8. $630.0 \mathrm{~nm}$ emission intensities in the vertical between 22:00 and 24:00 UT over Qaanaaq (upper panel) and optical emissions as observed from Qaanaaq (marked with Xs) compared with GPS TEC measurements from Thule, Greenland (plus symbols) approximately $100 \mathrm{~km}$ south of Qaanaaq (lower panel).

up into a chain of patches as it was transported anti-sunward into the polar cap.

Unlike the earlier event, however, the density enhancement corresponding to the second large patch was seen strongly in the TEC data measured over Greenland and Troms $\varnothing$, but not over Svalbard. As shown in Fig. $6 \mathrm{~b}$ and $\mathrm{c}$, it is apparent that the high-density plasma observed over Greenland by the optical instruments eventually reached Troms $\varnothing$ between 23:20 and 23:40 UT, but that this second patch followed a different trajectory to the first, passing significantly west of Svalbard, a point which will be further discussed in the next section. The density enhancements detected by the EISCAT Troms $\emptyset$ radar from 23:20 UT show no evidence of elevated electron temperature, consistent with the picture of plasma transport presented here. In this respect they are different from the density enhancements observed by the ESR around 23:00 UT, which were strongly correlated with electron temperature. 


\section{Discussion and conclusion}

The cross-polar transportation of high-density plasma is often seen during major storms. For example, Foster et al. (2005) found dense cold plasma streaming from the dayside ionosphere across the polar cap and into the night-side during the main phase of the 20 November 2003 storm. Large enhancements in the dayside TEC over the US mainland formed poleward streaming plumes of storm enhanced density. In this paper we have presented a multi-diagnostic approach to understanding the source and the development of such high-density plasma.

The GPS imaging provides an excellent context for explaining the chain of events over the whole Northern Hemisphere, covering the US sector, the polar cap and the European sector. Using the GPS imaging technique and global GPS measurements, supplemented by Kalman filtering based on a convection model driven by the measured IMF data, the flow of plasma from the dayside ionosphere across the polar cap into the northern Europe during this event is clearly illustrated. The ionisation produced by solar radiation at the lower latitudes became entrained into the high-latitude convection pattern, then convected via a tongue of ionisation which extended from subauroral latitudes into the polar cap. The extent to which the plasma is enhanced by precipitation as it enters the polar cap has not been established by the study here and that mechanism may also make a significant contribution to the patch density.

ISRs and optics can validate the imaging of ionospheric structures detected by the tomography method but are also complementary techniques, whose combination provides a considerable amount of additional information. For example, on the night side, polar patches with enhanced electron density in the high latitude northern ionosphere were observed by in-situ ISRs and optical instruments at separate sites in the late evening of 30 October 2003. Our interpretation is that the enhancements in F region electron density identified by the ESR during the period from 21:00 to 21:30 UT, and by the EISCAT Troms $\varnothing$ radar during the periods 21:30 to 22:00 UT and 23:15 to 23:40 UT on 30 October 2003, were not locally produced, but represented high density patches entrained in the rapid anti-sunward convection across the polar cap from the dayside ionosphere. The ionisation initially convected via a tongue of ionisation which extended from subauroral latitudes into the polar cap. By the time it reached Qaanaaq, however, it had broken up into a train of individual patches, closely following one another, but separated by localised regions of lower plasma density. The underlying assumption that plasma transportation in the polar-cap convection is sufficiently dominant and that velocity can be inferred from changes in the electron density maxima is validated here by the optical data. This is confirmed by the fact that the high convection velocities inferred from the GPS imaging were also observed in the smaller-scale optical imaging.

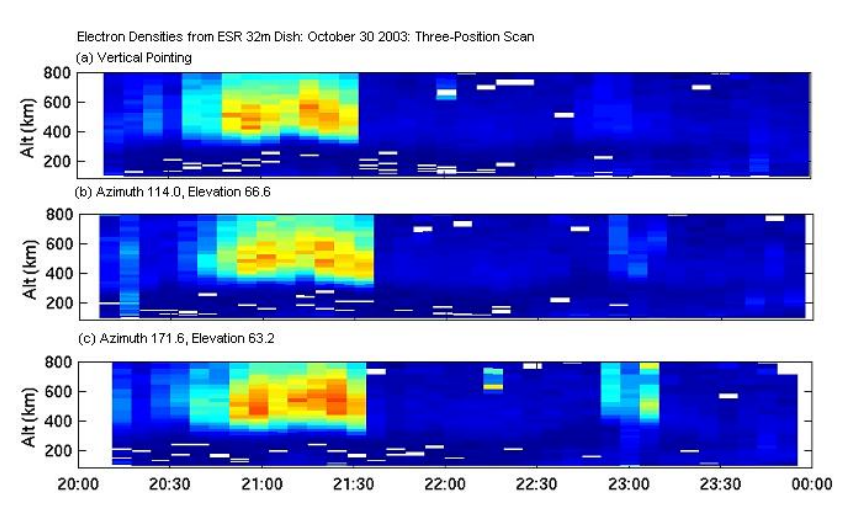

Fig. 9. Electron densities measured by the $32 \mathrm{~m}$ dish ESR at (a) vertical pointing, (b) azimuth $114.0^{\circ}$ and elevation $66.6^{\circ}$ and (c) azimuth $171.6^{\circ}$ and elevation $63.2^{\circ}$ between 20:00 and 24:00 UT. The colour axes are the same as those in the upper panels of Figs. 1 and 2 .

The combined use of GPS TEC maps and optical images provides a good explanation for the plasma density enhancements observed by the ESR during the period from 21:00 to 21:30 UT, and by the EISCAT Troms $\emptyset$ radar during the periods 21:30 to 22:00 UT and 23:15 to 23:40 UT. However, it does not explain the strong but short-lived density enhancement seen in the ESR data at around 23:00 UT (see Fig. 1). Although the ESR observed strongly enhanced density in the field-aligned direction, Fig. $7 \mathrm{~b}$ suggests that the overall TEC signature above Svalbard was much smaller than in the earlier event (only $22 \mathrm{TECu}$ at 22:55 UT, compared with $60 \mathrm{TECu}$ at 20:50 UT).

To better understand this second density enhancement at the ESR, we have examined the data from the ESR $32 \mathrm{~m}$ radar, which was scanning between three positions: vertical, east of the radar (azimuth $114^{\circ}$, elevation $66.6^{\circ}$ ) and south of the radar (azimuth $171.6^{\circ}$, elevation $63.2^{\circ}$ ). Figure 9 shows the time series of electron density data from each of these three positions. The colour axis on each panel is the same as those used in the upper panels of Figs. 1 and 2. It is very obvious that the enhanced density corresponding to the first main patch between 20:45 and 21:30 UT was seen in all three scan positions, suggesting a spatially extended feature. It also persisted longest in the southward and eastward directions, suggesting that the plasma was convecting south-eastwards, in agreement with the GPS TEC map and assumed convection pattern shown in Fig. $3 b$.

The density feature at around 23:00 UT, however, is seen strongly only in the field-aligned direction (by the ESR $42 \mathrm{~m}$ antenna). The $32 \mathrm{~m}$ antenna observed a weak signature in the southward scan direction, while the feature was almost undetectable in the vertical and eastward directions. Because the radar was scanning, and because it was only observing for $50 \%$ of the time (with the other $50 \%$ of observations being made on the $42 \mathrm{~m}$ dish), the ESR $32 \mathrm{~m}$ data obviously contain some temporal-spatial ambiguity. However, they suggest that 


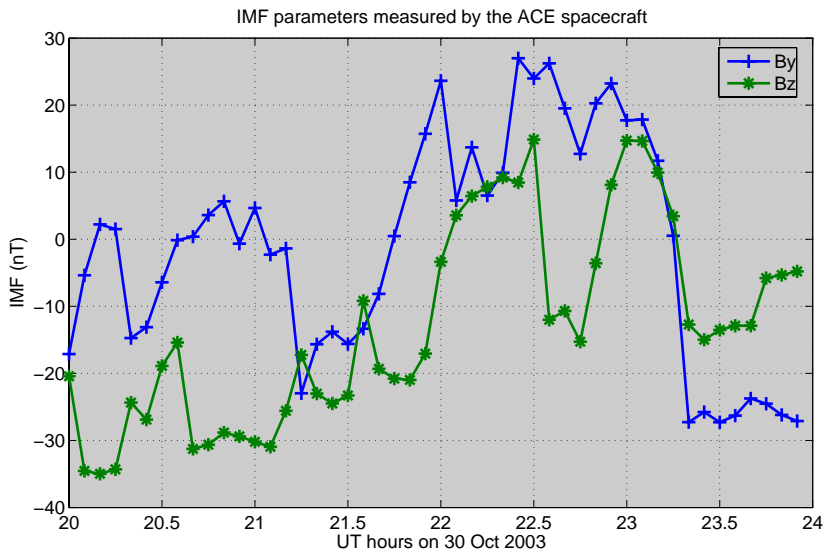

Fig. 10. IMF $B_{y}$ and $B_{z}$, variations vs. time every $5 \mathrm{~min}$ between 20:00 and 24:00 UT as measured by the ACE spacecraft.

the density enhancement seen by the $42 \mathrm{~m}$ antenna around 23:00 UT was either short-lived, spatially limited, or possibly both.

Another piece of evidence that this enhancement is different in character from the other density enhancements observed at the ESR and Troms $\varnothing$ is that, in the case of the 23:00 UT ESR event, the electron density enhancement is highly correlated with a strong enhancement in electron temperature, strongly suggesting the influence of soft particle precipitation, whereas all the other density enhancements are characterised by low electron temperature, suggesting plasma which has cooled in the course of being convected from elsewhere. While it might seem unusual for the second density enhancement to be located at such a high altitude if it were caused by soft particle precipitation, we note that the thermospheric conditions during this interval were very unusual, with Sutton et al. (2005) having established from CHAMP accelerometer data that neutral densities at $\sim 410 \mathrm{~km}$ were enhanced by up to $300 \%$ during this time. This also argues for a higher altitude of the $630 \mathrm{~nm}$ emissions (and therefore a larger convection velocity from the optical measurements), which are considered to originate from an altitude range approximately one neutral scale height below the F-region peak.

The ACE IMF measurements of IMF $B_{y}$ and $B_{z}$, shown in Fig. 10, also offer support to the idea that the 23:00 UT density enhancement seen at the ESR might not be due to a convecting plasma patch. Due to the solar wind velocity, a time lag of approximately 25 min should be applied for the solar wind observed at the L1 point to reach the Earth. This means that the first patch, observed at the ESR from 20:45 to 21:30 UT, is drifting in a convection pattern dominated by negative $B_{z}$ and $B_{y}$ conditions, (i.e. those observed by the spacecraft between 20:20 and 21:05 UT). However, the convection pattern around 23:00 UT reflects IMF observations at ACE around 22:35 UT, by which time the IMF was turning to southward $B_{z}$ and positive $B_{y}$ conditions. The consequent reconfiguration of the high-latitude convection, coupled with the rotation of the Earth, which takes the ESR further into the dawn cell, might explain why the second convecting plasma patch apparently passed quite far to the west of Svalbard, though its eastward edge still extended into northern mainland Scandinavia (see Fig. 8). The ACE data also show two brief intervals of northward IMF $B_{z}$ (from around 22:00 to 22:30 UT and 22:45 to 23:15 UT), which would have been expected to reconfigure both the convection and the pattern of auroral precipitation. It is well-known that northward IMF can produce polar auroral structures such as sun-aligned arcs and theta auroras, providing a possible explanation for the brief appearance of direct precipitation signatures above Svalbard, though we lack any direct evidence to support such a conjecture.

Previous work by Stolle et al. (2006) and Mitchell et al. (2005) also observed the same anti-sunward polar TOI over the north polar ionosphere in the evening of 30 October 2003 and associated scintillations. However, neither of these previous studies used a time-dependent imaging method capable of estimating the plasma velocity and were therefore not able to provide evidence to distinguish between precipitation and transportation, both of which can contribute to the source of the patches observed over Europe. It is apparent from this study that the horizontal motion of the plasma between 20:00 and 24:00 UT on 30 October was mainly influenced by the $\boldsymbol{E} \times \boldsymbol{B}$ convection in the polar ionosphere and that this was the main cause of the ionisation patches seen over Europe. Nevertheless, precipitation cannot be ignored and may make a small but significant contribution to enhancements in the electron density.

In conclusion, we have shown how tomographic imaging based on GPS observations and Kalman filtering, allied to a convection model driven by measured IMF data, provides a powerful tool for imaging the density structure of the northern polar ionosphere and explaining the chain of events over the whole Northern Hemisphere during the second night of the Halloween Storm, covering the US sector, the polar cap and the European sector. We have shown that these GPS results are consistent both with optical observations of propagating polar patches made from Greenland, and with density measurements made by the EISCAT radars at Svalbard and Troms $\varnothing$. Finally we have shown how the combination of such observations can be used to interpret specific features in a given data set, with particular reference to the two density enhancements observed by the ESR. We believe that the use of GPS TEC maps of the kind shown here, in conjunction with other high-latitude data sets, provide a very useful basis for future studies of high-latitude morphology and dynamics.

Acknowledgements. The authors acknowledge the use of GPS data provided by IGS and the ACE data from the ACE Science Center at Caltech. EISCAT is an international association supported by China (CRIRP), Finland (SA), Germany (DFG), Japan (NIPR and STEL), Norway (NFR), Sweden (VR) and the United Kingdom (STFC). PY 
and CNM are also grateful to the support of the UK EPSRC. Work at AFRL was carried out under AFOSR task 2311AS. Thanks are also given to the two referees for their constructive suggestions.

Topical Editor M. Pinnock thanks J. Sojka and another anonymous referee for their help in evaluating this paper.

\section{References}

Bust, G. S. and Mitchell, C. N.: History, current state, and future directions of ionospheric imaging, Rev. Geophys., 46, RG1003, doi:10.1029/2006RG000212, 2008.

Crowley, G.: Critical review of ionospheric patches and blobs, edited by: Stone, W. R., Rev. Radio Sci., 1993-1996, 1996.

Doherty, P., Coster, A. J., and Murtagh, W.: Eye on the ionosphere: space weather effects of October-November 2003, GPS Solutions, 8(4), 267-271, doi:10.1007/s10291-004-0109-3, 2004.

Foster, J. C. and Rideout, W.: Midlatitude TEC enhancements during the October 2003 superstorm, Geophys. Res. Lett., 32, L12S04, doi:10.1029/2004GL021719, 2005.

Foster, J. C., Coster, A. J., Erickson, P. J., Holt, J. M,, Lind, F. D., Rideout, W., McCready, M., van Eyken, A., Barnes, R. J., Greenwald, R. A., and Rich, F. J.: Multiradar observations of the polar tongue of ionization, J. Geophys. Res., 11, A09S31, doi:10.1029/2004JA010928, 2005.

Mitchell, C. N., Alfonsi, L., De Franceschi, G., Lester, M., Romano, V., and Wernik, A. W.: GPS TEC and scintillation measurements from the polar ionosphere during the October 2003 storm, Geophys. Res. Lett., 32, L12S03, doi:10.1029/2004GL021719, 2005.

Rishbeth, H. and Williams, P. J. S.: The EISCAT ionospheric radar: the system and its early results, Q. J. R. Astr. Soc., 26, 478-512, 1985.

Rodger, A. S., Pinnock, M., Dudeney, J. R., Watermann, J., de la Beaujardiere, O., and Baker, K. B.: Simultaneous two hemisphere observations of the presence of polar patches in the nightside ionosphere, Ann. Geophys., 12, 642-648, 1994,

http://www.ann-geophys.net/12/642/1994/.
Sojka, J. J., Schunk, R. W., Bowline, M. D., and Crain, D. J.: Ambiguity in identification of polar cap F-region patches: contrasting radio and optical observation techniques, J. Atmos. Solar-Terr. Phys., 59, 249-258, 1997.

Spencer, P. S. J. and Mitchell, C. N.: Imaging of fast moving electron-density structures in the polar cap, Annals Geophysics, 50(3), 427-434, 2007.

Stolle, C., Lilensten, J., Schluter, S., Jacobi, Ch., Rietveld, M., and Lühr, H.: Observing the north polar ionosphere on 30 October 2003 by GPS imaging and IS radars, Ann. Geophys., 24, 107113, 2006, http://www.ann-geophys.net/24/107/2006/.

Sutton, E. K., Forbes, J. M., and Nerem, R. S.: Global thermospheric neutral density and wind response to the severe 2003 geomagnetic storms from CHAMP accelerometer data, J. Geophys. Res., 110, A09S40, doi:10.1029/2004JA010985, 2005.

Wannberg, G., Wolf, I., Vanhainen, L.-G., Koskenniemi, K., Röttger, J., Postila, M., Markkanen, J., Jacobsen, R., Stenberg, A., Larsen, R., Eliassen, S., Heck, S., and Huuskonen, A.: The EISCAT Svalbard radar: a case study in modern incoherent scatter radar system design, Radio Sci., 32, 2283-2307, doi:10.1029/97RS01803, 1997.

Weimer, D. R.: Models of high-latitude electric potentials derived with a least error fit of spherical harmonic coefficients, J. Geophys. Res., 100, 19595-19607, 1995.

Yin, P., Mitchell, C. N., Spencer, P. S. J., and Foster, J. C.: Ionospheric electron concentration imaging using GPS over the USA during the storm of July 2000, Geophys. Res. Lett., 31, L12806, doi:10.1029/2004GL19899, 2004.

Yin, P., Mitchell, C. N., and Bust, G.: Observations of the F region height redistribution in the storm-time ionosphere over Europe and the USA using GPS, Geophys. Res. Lett., 33, L18803, doi:10.1029/2006GL027125, 2006. 